\title{
Teen pregnancy policy: an analysis of the healthy teens act
}

\begin{abstract}
The purpose of my research paper is to analyze the proposed bill called the Healthy Teens Act. This bill would provide grant funding for comprehensive sexual education programs in New York State. The Healthy Teens Act would also establish standards for all programs receiving funding including medical accuracy, providing culturally appropriate and unbiased information, family communication, and healthy decision-making skills. The Healthy Teens Act would award grants to programs that exemplify these standards and would set high-need communities as a priority. Currently, there is no legal mandate for schools to teach sexual education in public schools in New York State, with the exception of HIV/AIDS education. The only incentive given to schools is federal funding for abstinenceonly sexual education programs. In my paper, I compare the two different types of programs and their approaches to providing sexual education. I ultimately hope to show how a comprehensive sexual education program would ultimately be more effective in reducing teen pregnancy rates.
\end{abstract}

Keywords: teen pregnancy, legal mandate, pregnant, abortion rates, health disparities, syracuse
Volume 3 Issue 2 - 2015

\author{
Rachael Donovan \\ SUNY Upstate Medical University/Maxwell School of Syracuse \\ University, USA
}

\begin{abstract}
Correspondence: Rachael Donovan, SUNY Upstate Medical University/Maxwell School of Syracuse University, USA, Tel 3155060060, Email rachaelisnt@gmail.com
\end{abstract}

Received: December 17, 2014 | Published: December II, 2015
Abbreviations: FPS, family planning service; SCSD, syracuse city school district; NYCLU, new york civil liberties union

\section{Executive summary}

Teen pregnancy rates for New York State have climbed above the national average. New York State's teen pregnancy rate of 61.9 per 1000 females largely exceeded the Healthy People 2010 goal of 43 per 1000 females. ${ }^{1,2}$ This provides an opportunity to re-think current New York State strategies and policies to combat the problem of teen pregnancy. Currently, New York State has not implemented any legal mandate for schools to teach sexual education or any state standards when sexual education is taught. This poses a problem for communities plagued by teen pregnancy. By zip code, Downtown Syracuse (13202) has the highest teen pregnancy rate in the entire state - 209.9 per 1000 females. $^{3}$ Using the policy analysis methodology, I compared three approaches to sexual education including abstinenceonly, abstinence-plus, and comprehensive. I evaluated each policy based on five criteria. The results of the policy analysis yielded that a comprehensive approach is the most effective, efficient, cost effective, and most accepted policy with low-moderate institutional constraints.

The proposed legislation called the Healthy Teens Act would provide funding for comprehensive sexual education programs and would also establish state standards for teaching sexual education in public schools. In recent years, New York State sexual education programs have been evaluated by medical professionals to contain medical inaccuracies and to contain cultural and gender stereotypes. The Healthy Teens Act would require programs to meet specific content requirements and educational standards in order to receive funding. This policy report is a call to action for policymakers and targets a variety of key stakeholders including Planned Parenthood, Family Planning Service (FPS), the Syracuse City School District (SCSD), New York State taxpayers, parents of sexually active teenagers, as well as teens themselves. This report aims to provide a clear sense of direction on how to update sexual education policies and approaches, resulting in a reduced teen pregnancy rate. The next steps in enacting this legislation are to provide a network of support for the bill and to ensure community awareness of the bill.

\section{Methods and materials}

\section{Defining the problem}

Teen pregnancy is a widespread concern in the United States. According to the Center for Disease Control, the current teen birth rate for the United States is roughly 34.3 births per 1000 women. ${ }^{1}$ This rate has been steadily decreasing since its ultimate peak in 1991 of 61.8 births per 1000 females aged 15-19. Although this rate is the lowest rate on record for the United States, our rate is still "three times the rate of Canada, four times the rate of France and Germany, and eight times the rate of Japan". ${ }^{1,4}$ Teen pregnancy has been placed on the New York State Department of Health Prevention Agenda for 2013-2017 as one of the health improvement areas. Furthermore, the Community Health Assessment forums identified teen pregnancy as a prevalent concern in Onondaga County. There is a significant difference between the teen pregnancy rate and the teen birth rate. The birth rate is defined as the rate of babies being born to women aged 15-19 and is a concrete and reportable number. The rate of teen pregnancies is usually defined as the number of pregnancies per 1000 women between age 15-19 when the pregnancy ended and is essentially an estimate on how many teens have become pregnant. This estimate is calculated using abortion, birth and miscarriage rates for this age group. For the purposes of this policy report, the teen birth rates will be the primary statistics. There are several factors which make the teen pregnancy statistics in the United States so shocking. Important to note is the difference in teen birth rates between white, black, and Hispanic women. The teen birth rates for Hispanics and Non-Hispanic blacks are double the rate of Non-Hispanic whites. ${ }^{1}$ In 2011, the birth rate for Non-Hispanic white females aged $15-19$ was roughly 24 per 1000 . In the same year, 
the birth rates for Non-Hispanic black females and Hispanic females of the same age were approximately 49 per 1000 and 52 per 1000 respectively. ${ }^{1}$ It is troublesome to think that race and ethnicity could be such an important factor among these rates. Unfortunately, race and ethnicity are characteristics for which health disparities are ever present and according to the Guttmacher Institute, this gap between races is only getting larger. This is illustrated in the following graph Figure 1.While this graph shows that the teen birth rates are declining, it is important to remember that the United States also has the highest abortion rate of any industrialized nation. ${ }^{1,5}$ Furthermore, New York State has the highest abortion rate of any state in the U.S. with 37 abortions per 1000 females aged $15-19$ in 2008. ${ }^{1,6,7}$ These higher abortion rates lead to a lower birth rate among teens, even though the original pregnancy rate was much higher.

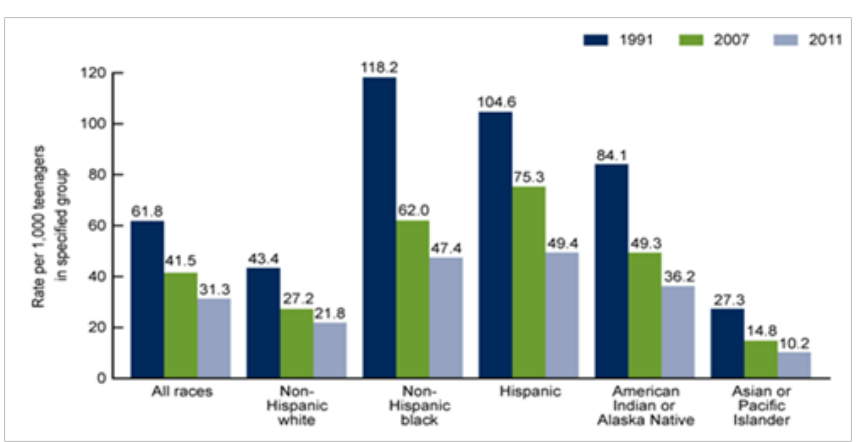

Figure I Birth rates for teenagers aged I5-19, by race and Hispanic origin: United States, 1991, 2007and 20II.

Teen childbearing is a pressing issue because there are undesirable consequences, both healths related and non-health related. A teen mother's mental health is greatly impacted by the stress of having a child at such a young age and, generally, as a single mother. As a result, teen mothers are more likely to have mental health conditions such as depression, anxiety, and bipolar disorder., ${ }^{5,8-11}$ This means that hundreds of thousands of teen women each year are at risk for developing these potentially dangerous conditions. Raising a child is challenging enough for most teen women, but to have their mental health at stake has the potential to lead to more serious breakdowns such as suicidal thoughts or actions, self harm, or even child abuse. ${ }^{5,8-11}$

There are also negative consequences for the children of teen parents. Since pregnant teens are less likely to receive consistent prenatal care, infants born to teen moms have an increased risk of being born premature or having a low birth weight. "This puts newborns at greater risk for infant death, respiratory distress syndrome, bleeding in the brain, vision loss, and intestinal conditions". $1,5,8,9,11$ Being raised by a teen parent is an important factor to consider in the future of the children. ${ }^{12}$ "The daughters of teen mothers are $22 \%$ more likely than their peers to become a teen mom and sons of teen moms have a $13 \%$ greater chance of going to prison". ${ }^{8-11,13}$ This unfortunate fact keeps the cycle of teen pregnancy going.

Teen parents are also undereducated. Only $50 \%$ of teen moms get a high school diploma by age 22 , less than $33 \%$ finish high school and receive a diploma on time and by age 30 only $1.5 \%$ of teenage mothers receive a college degree. ${ }^{8}$ Since jobs which require at least a two year college degree are on the rise, this presents a large problem for the future of a teen parent and their socioeconomic status. This is exemplified in how many teen mothers go on some sort of public assistance. Roughly $80 \%$ of unmarried teen mothers are on some sort of public assistance such as WIC, SNAP, or welfare and "almost $50 \%$ of unmarried teen mothers go on welfare within one year of giving birth:". ${ }^{9} 11,13$ This statistic shows that the lack of secondary education in these women, combined with the fact that they are so young and lack their own funds, leads to a problem paid for with taxpayer dollars. While it is understandable why these women would need access to public assistance programs, teen pregnancy and childbirth ultimately bear long-term costs for society as well as the economy.

"In 2008, teen pregnancy and childbirth accounted for nearly \$11billion per year in costs to U.S. taxpayers for increased health care and foster care, increased incarceration rates among children of teen parents, and lost tax revenue because of lower educational attainment and income among teen mothers". ${ }^{1,5,8,9,11}$ This presents a huge economic impact for the United States. Also in 2008, teen pregnancy and childbearing cost New York State taxpayers roughly \$377million. ${ }^{5,8}$ This includes: "\$176million for public health care (Medicaid and CHIP); \$211million for child welfare; and, for children who have reached adolescence or young adulthood, \$150million for increased rates of incarceration and \$126million in lost tax revenue due to decreased earnings and spending". ${ }^{5,8}$ Using the Cost of Teen Pregnancy Calculator from Thenationalcampaign.org, I calculated the costs to Onondaga County, based on the teen birth rate. In 2009, the teen birth rate for Onondaga County was roughly 50 per 1000 females aged 15-19. The cost to Onondaga County residents was $\$ 1,074,100$ per 50 babies born. ${ }^{5}$ Put in terms of county costs, the economic impact hits closer to home. Teen birth rates in Onondaga County are inconsistent with the rest of the state. Thus, rates have not been steadily declining. Instead, the rates declined slightly from 2000-2004 and actually increased in 2003. Since 2004, the rates in Onondaga County have been simply leveling out at almost double the teen birth rate of New York State. ${ }^{14}$

Teen pregnancy rates in the city of Syracuse are especially troublesome. In the 13202 zip code which surrounds the heart of Syracuse, teen pregnancy rates are 209.9 per 1000 . This is the highest rate in the entirety of New York State zip codes. In the 13204 zip code of the city's West side district, teen pregnancy rates are 185.3 per 1000. In the 13205 zip code of the city's South side district, teen pregnancy rates are 177.4 per $1000 .^{3,14}$ When juxtaposed with the 13031 zip code of Camillus, which is only 15 minutes away from the city, the rate is 20.2 and we can clearly see how rampant teen pregnancy is within the city of Syracuse. ${ }^{3,14}$ Taking into account all of the previously stated costs of teen pregnancy and being born to a teen mom, this is an extremely urgent issue.

Syracuse is in dire need of reversing these worrisome statistics and it appears to be the epicenter of the teen pregnancy problem in Onondaga County. With this astronomical teen pregnancy rate, several questions need to be addressed. What affects teen pregnancy rate? What can be done to decrease the teen pregnancy rate? And most importantly: Why is Syracuse's teen pregnancy rate the highest in the state, when compared by zip codes? The answers are complex and include many different factors. For example, Syracuse houses a large refugee population. Cultural differences among refugee women lead to different opinions and social norms for birth control methods. While there is no definitive statistic of the number of babies born to teen refugees, this is a factor that ultimately increases teen pregnancy rates in Syracuse. Another factor to consider is the lack of access to reproductive health care. One important factor is socioeconomic status.

The poverty rate in Onondaga County is among the highest recorded in the past two decades. Roughly $15.6 \%$ of the total population in Onondaga County is at or below the poverty level. ${ }^{14}$ When broken 
down by age, the poverty statistics are even more shocking. $22.5 \%$ of children under age 18 in Onondaga County are living in poverty. ${ }^{14}$ Furthermore, the poverty rate in the City of Syracuse is roughly $35 \%$ - more than double the county rate. Teen women with a lower socioeconomic status are more at risk of becoming pregnant due to sociocultural norms, a lack of rigid family structure, and perceived barriers to higher education or a career. ${ }^{1,2,5,11}$ One of the biggest factors affecting the teen pregnancy rates, and perhaps the easiest to improve upon, is sexual education.

\section{Weighing the options}

There are mainly two ways to approach sexual education in schools. One way is the abstinence-only method. This approach is longestablished and focuses on telling teens that they should not have sex because there are severe consequences. This method rarely includes information on birth control methods other than simply abstaining from sex. Thus, when the teen does engage in sexual behavior, they are unaware of the different methods to use in order to protect themselves from pregnancy and STDs. ${ }^{15}$ Unfortunately, this method of instruction has been proven to be extremely ineffective because it does not stop teen sexual behaviors. Rather, this approach conceals all teen sexual activity and fuels an environment that condones sweeping it under the rug. According to abstinence education studies evaluated by the Community Preventive Services Task Force, there was "insufficient evidence to conclude the effectiveness of groupbased abstinence education interventions delivered to adolescents to prevent pregnancy, HIV and other sexually transmitted infections". ${ }^{16}$ Furthermore, while teen sexual activity decreased by roughly $16 \%$, pregnancy actually increased by $12 \%{ }^{16}$ Abstinence education was also shown in the studies to have no effect on number of sexual partners, use of protection, or unprotected sexual activity. ${ }^{16}$

"A 2007 report by the New York Civil Liberties Union (NYCLU) found that abstinence-only-until marriage programs in New York State had used curricula that have been evaluated by experts to contain medical inaccuracies, religious content, sex stereotypes, and bias against LGBT youth". ${ }^{17}$ These programs covered birth control methods only to highlight and sensationalize their failure rates. Thus, students are submitted to demeaning scare-tactics and do not know how to protect themselves or their partners from STDs or pregnancy. This puts sexually-active teens at a greater risk for pregnancy and sexually-transmitted diseases. ${ }^{17,18}$

The second approach to sexual education is comprehensive. This method includes information about birth control methods, STD's, and includes abstinence as an option, but not a requirement. Research has shown that teens with comprehensive sex education are $60 \%$ less likely to become pregnant or to get someone else pregnant. ${ }^{12}$ When the Community Preventive Services Task Force evaluated comprehensive risk-reduction studies, the results showed favorable health outcomes such as "reducing a number of self-reported risk behaviors (engagement in any sexual activity, frequency of sexual activity, frequency of unprotected sexual activity, and number of partners), increasing the self-reported use of protection against pregnancy and STIs, and reducing the incidence of self-reported or clinically-documented sexually transmitted infections". ${ }^{16}$ These favorable outcomes of a comprehensive approach are also clearly reflected in the states with the highest and lowest teen pregnancy rates. Mississippi had the highest teen birth rate in 2011 with 64.2 live births per 1000 females aged 15-19. Mississippi also stresses abstinence-only education in public schools. ${ }^{1,19,20}$ On the other hand, New Hampshire requires comprehensive sexual education in its public schools. As a result,
New Hampshire had the lowest teen birth rate in 2011 with 16.4 births per 1000 females aged 15-19.,19,20 This is a clear indication that a comprehensive approach to sexual education is the most beneficial in reducing teen pregnancy. Unfortunately, many states are not changing their educational policies and are sticking to the long-tried, long failed abstinence-only method of sexual education. This is due to the fact that these programs are federally funded, creating an incentive for states to use this method. New York State is no exception. "In 2006, New York received a total of $\$ 10,664,612$ in federal abstinence-only-untilmarriage funds the third largest pool of abstinence-only dollars (after Texas and Florida) in the country". ${ }^{17}$ In this same year, no federal or state funds were allocated for comprehensive sex education programs in New York State.

The Health Education Coordinator for Family Planning Service, Tiffany Lloyd, was able to shed some light on local sexual education practices. The majority of public schools in Onondaga County lightly covers sexual education topics, but do not provide in-depth education. This sexual education approach is referred to as abstinence-plus. Most of these curricula include "Anatomy and physiology of the reproductive organs, overview of STD's, overview of birth control options and discussions about healthy relationships". ${ }^{21}$ Generally, abstinence-plus leans towards a more comprehensive sexual education model, but LGBTQ education is usually not included in these health curricula. This depends upon the teacher and the environment in the school district including the school administration, the school board, and the PTO. ${ }^{21}$ These programs are provided on an opt-in basis and parents have the right to pull their child out of class while these topics are being taught. The current situation surrounding local abstinenceplus programs stems from a significant decrease in school budgets over the past several years. Many courses, including Health, have been reduced and condensed into one semester when previously a year of instruction would be used to cover the topic. Students are left with a very basic context of these topics, but schools do not have enough time or money to do a more thorough job. ${ }^{21}$ The larger problem is that these programs are not regulated and can include any information, being true or false.

In a cross-sectional analysis of pregnancy prevention education in public secondary schools, the percentage of schools in 2011 which covered pregnancy prevention was significantly down in 11 states across the country since $2008 .{ }^{22}$ The report indicated that no state percentage was significantly higher from 2008. Additionally, "the percentage of schools in which all three condom-related topics were taught in a required course in grades 9-12 was significantly lower in eight states and significantly higher in three states". ${ }^{22}$ The result is that teens become unaware about their reproductive biology. According to a new study done by the CDC, teens are unconscious of their chances of getting pregnant or getting someone else pregnant while having unprotected sex. "In the survey of roughly 5000 teen mothers with unintended pregnancies, about a third said they did not use birth control because they did not think they could get pregnant". It is troublesome to think that there are still teens in the United States who is unmindful to the risks of having unprotected sex. On the other hand, this statistic seems to fit the current trend of abstinence-only education policies and methods. We cannot afford to continue on this path. Delaying pregnancy may give young women the chance to get the higher education they need which will hopefully lead to a path out of poverty for these women. If teen pregnancy rates remain high, teen mothers will continue to develop mental health problems and give birth to developmentally delayed babies who in turn become teen parents. Taxpayers will continue to pay billions of dollars each year 
to cover teen pregnancy costs and other related expenses. In order to decrease these rates, New York State must recognize the need to implement comprehensive sexual education programs in public schools, as well as standards for those programs.

\section{Finding the solution}

A proposed legislation, the Healthy Teens Act, would provide funding for comprehensive sexual education programs. This bill is the next crucial step in implementing effective pregnancy prevention programs in New York State and updating state requirements for teaching sexual education. The Healthy Teens Act (HTA) is a bill "to amend public health law, in relation to establishing the age-appropriate sex education grant program". ${ }^{23}$ It was created when New York State's teen pregnancy rate of 61.9 per 1000 females largely exceeded the Healthy People 2010 goal of 43 per 1000 females. The HTA would create a program headed by the New York State Commissioner of Health, who would work with the Commissioner of Education to establish a medically accurate, age-appropriate sexual education grant program. These grants would be used to assist educational agencies in developing programs that are "specifically aimed at reducing and preventing unwanted teen pregnancies and the occurrences of STDs among youth in New York State". ${ }^{24}$

Furthermore, the HTA would prioritize funding to communities with the highest rates of teen pregnancy and STD cases among adolescents. ${ }^{24}$ This includes Onondaga County's zip codes of 13202 , 13204, and 13205-the City of Syracuse. Unfortunately, as previously stated, the zip code of 13202 has the highest rate of teen pregnancy in New York State, with a rate of roughly 209.9 per 1000 . The grants provided by the Healthy Teens Act would be awarded annually to school districts, school-based health centers, and community-based organizations which fit the determined HTA criteria for comprehensive sexual education. In order to receive these funds, "the program must:

1. Be medically accurate and age-appropriate;

2. Not teach or promote religion or religious views;

3. Teach abstinence as the only sure way to avoid pregnancy or STDs;

4. Stress the value of abstinence without ignoring adolescents who have had or are having sexual intercourse;

5. Provide accurate, unbiased information about the benefits and side effects of all contraceptives and barrier methods in preventing pregnancy and STDs;

6. Teach skills which enable students to make responsible decisions regarding sexual and intimate relationships;

7. Discuss the influence of alcohol and drugs on decision-making;

8. Encourage parental involvement and family communication about sex and sexuality;

9. Help students develop healthy attitudes, strong self-esteem, and valuable life skills in all of these areas". ${ }^{17,24}$

These requirements of the HTA are very clear and specific to how they are trying to reduce rates of teen pregnancy and STDs. This outlines a foundation for school districts and community organizations to follow during the implementation of comprehensive education programs. If the HTA were implemented, these standards would be up-to-date with other states that have implemented comprehensive sexual education policies. In comparison with most states, the HTA standards are leading the way for sexual education programs and their requirements. In addition, the HTA standards well outweigh New York's current lack of guidelines for teaching sexual education. Under the current law, New York does not have a state-wide mandate for schools to teach any sort of sexual education. The only topic required by current state law is HIV/AIDS education. Unfortunately, the HIV/ AIDS education is not mandated under current law to be "medically accurate or culturally appropriate and unbiased, and is able to promote religion". ${ }^{6}$ Furthermore, New York schools are not required to include life skills such as avoiding coercion, healthy decision-making, or family communication. ${ }^{6}$ Due to a lack of standard requirements, school districts are able to include essentially whatever they want in the curriculum. The HIV/AIDS education is also not covered by state funding. Without a legal mandate or funding source, school districts in New York State do not have any incentive to implement comprehensive sexual education programs. ${ }^{17}$ The Healthy Teens Act would change this by providing funding streams for comprehensive sexual education programs. According to the Guttmacher Institute, less than half of the states require some sort of sexual education to be taught in schools. "22 states and the District of Columbia mandate sex education; 20 states and the District of Columbia mandate both sex education and HIV education". ${ }^{6}$ Whether this instruction is beneficial to students or not remains questionable when the state policies of requirements for sex and HIV education are further explored.

" 27 states and the District of Columbia mandate that, when provided, sex or HIV education programs meet certain general requirements. 13 states require that the instruction be medically accurate. 26 states and the District of Columbia require that the information be appropriate for the students' age. 8 states require that the program must provide instruction that is appropriate for a student's cultural background and not be biased against any race, sex, or ethnicity. 2 states prohibit the sexual education programs from promoting religion". ${ }^{6}$

This paints an incredibly disturbing picture of what sexual education entails in most schools across the United States. New York State is no exception. Many taxpayers would assume that any form of education in public schools must be accurate and be culturally unbiased. In the case of sex education, this assumption is incorrect. This opens the opportunity for these programs to provide false information and to discriminate against certain social, cultural and ethnic groups. As previously stated, New York State sex education programs that were evaluated by medical professionals were found to be medically inaccurate and also promoted religious beliefs, sex/ gender stereotypes, and bias against the LGBT community. ${ }^{17}$ As shown in the following chart from Guttmacher Institute, there is no state mandate for schools to do otherwise. Thus, a complete reform of New York State law regarding sexual education programs is completely necessary (Figure 2).

Many states require some form of parental communication and involvement in sex or HIV education. "37 states and the District of Columbia require school districts to involve parents in sex education, HIV education, or both. 22 states and the District of Columbia require that parents be notified that sex education or HIV education will be provided. 3 states require parental consent for students to participate in sex education or HIV education; 35 states and the District of Columbia allow parents to remove their children from instruction". ${ }^{6}$ Family communication on this subject can be very beneficial for students. It allows for open and honest discussion between parents and their teens. This allows for the opportunity to discuss important topics 
like birth control prescriptions, STD tests, and gynecological exams for young women. The HTA would require its sex education programs to involve parents on these topics, which would make parents feel that they have a voice in how their children are taught (Figure 3). While family communication about sex is important, it seems problematic that states would require, rather than encourage, parental consent for student participation. Similarly, it is obstructive to allow parents to remove their children from instruction. This does not empower the teen to make responsible choices for their own well-being and knowledge. Rather, it allows the parents to control what their teen will or will not be educated about, without taking into consideration their teen's wants or needs. This reinforces the negative connotation that sexual education has developed-that educating teens about birth control methods and STDs will encourage them to have sexual intercourse. Thus, teens are left without a functional knowledge of birth control methods, STDs, or healthy decision-making.

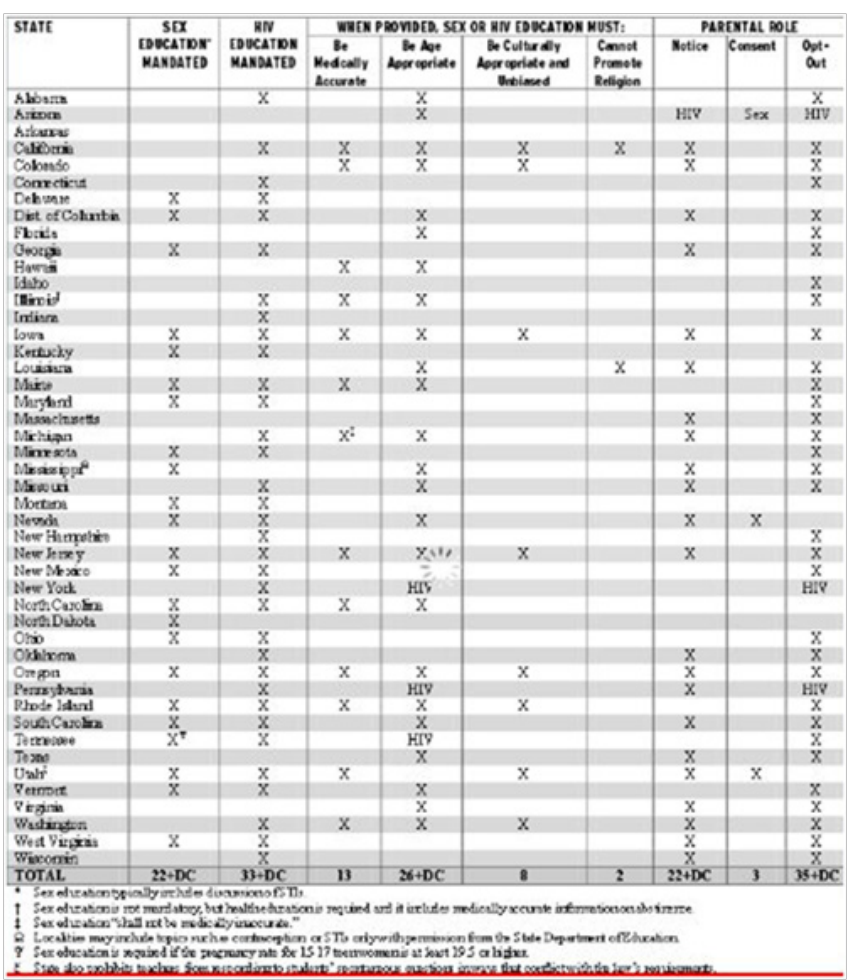

Figure 2 General Requirements: SEX and HIV Education.

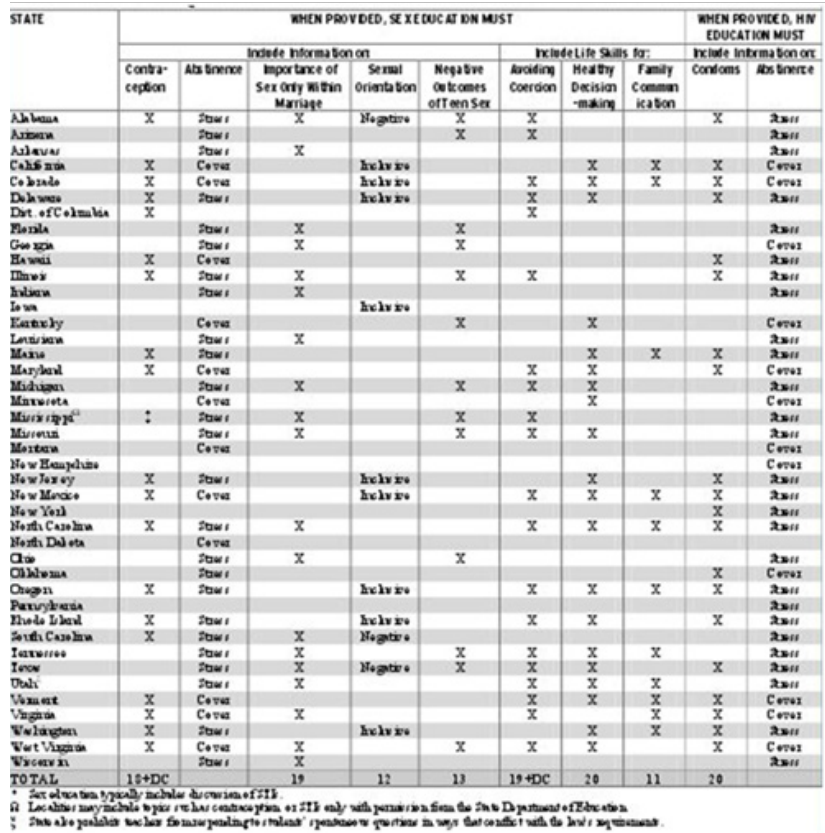

Figure 3 Content requirements for SEX and HIV Education. 
Furthermore, allowing parents to opt-out their teen ignores the fact that teens will, and do, have sexual intercourse regardless of their parents' wishes. According to the CDC's 2011 Youth Risk Behavior Survey, $42 \%$ of high school students in New York State who were surveyed said they had ever had sexual intercourse. ${ }^{25,26} 31 \%$ of high school students said that they had sexual intercourse with at least one person in the three months prior to the survey. ${ }^{25,26}$ Of this percentage, $37 \%$ did not use a condom during the last sexual encounter and $79 \%$ did not use birth control pills, birth control implant/injection, or a birth control ring. ${ }^{25,26}$ Disturbingly, 22\% said that they had used drugs or alcohol before the last sexual encounter. ${ }^{25,26}$ The reality is that teens have sex and programs must be put into place to educate them on how to prevent themselves from becoming pregnant or developing an STD.

\section{Policy analysis of the healthy teens act}

In order to determine whether or not the Healthy Teens Act provides the answer to the question of teen pregnancy prevention, there are several policy details to consider; its effectiveness, its efficiency, any institutional constraints, and community acceptance/ political feasibility. Using these evaluation criteria, we are able to further understand the Healthy Teens Act. In order for a policy to be considered, it must first be considered an effective strategy. The Healthy Teens Act's strategy uses comprehensive sexual education to fully educate teens in New York State. As previously stated, teens with exposure to comprehensive sexual education are $60 \%$ less likely to become pregnant or to get someone else pregnant. ${ }^{12}$ This is also exemplified in the states with the highest and lowest rates of teen pregnancy. ${ }^{1,19,20}$ It seems that the Healthy Teens Act strategy would be effective, according to the general success of the comprehensive sexual education strategy. An abstinence-only approach would not be considered an effective strategy because it leaves teens without the concrete and accurate information they need. Also, New York State schools have been continuously applying this method without any success. An abstinence-plus approach would be slightly more effective than abstinence-only because this approach does include some information, albeit limited, about birth control methods. A comprehensive strategy would be the most effective strategy.

Unfortunately, a fundamental problem with an education strategy is that many of the high-risk females drop out of school at a young age, before they are able to take a Health course. The Syracuse City School District has a drop-out rate of nearly half, with a reported graduation rate of roughly $48 \%{ }^{27}$ Furthermore, roughly $50 \%$ of those students that graduated were African American. ${ }^{27}$ In order to combat this high drop-out rate, the community organizations must pick up where the schools left off and implement sex education curricula for drop-outs.

The next area of evaluation is efficiency. We may question whether the policy costs outweigh the policy benefits. The HTA seems to make good use of resources and funding because it allocates the grant funds to high-need areas. Areas with high rates of teen pregnancy would be considered priority areas. Thus, the HTA aims to stop the problem at its roots. Under the Healthy Teens Act, Onondaga County and the City of Syracuse would be considered priority areas, due to the high rate of poverty, teen pregnancy as well as the inconsistencies with the rest of New York State. Onondaga County and the City of Syracuse would receive grants to establish and maintain comprehensive sexual education programs in order to combat this problem.
From a financial standpoint, the HTA seems very cost-effective. Taxpayers would not have to retrieve more money from their own pockets. Rather, the money would come from a federal source. Currently, taxpayers are paying taxes for a proven ineffective strategy. The HTA gives taxpayers more for their money by promoting the successful comprehensive sexual education structure. In turn, this would lead to less money spent on teen pregnancy and associated childbearing costs such as Medicaid, child welfare, incarceration rates, and lost tax revenue due to decreased earnings and spending. These costs totaled \$377million to New York State taxpayers in 2008. ${ }^{5}$ Abstinence-only and abstinence-plus are not cost-effective strategies because they do not save money or have any long term gains. On the contrary, they cost more money in the long run due to higher pregnancy related costs. The next areas of evaluation to be considered are institutional constraints. In other words, it must be determined if the Healthy Teens Act seems to fit into existing policies and current legislation. Recently enacted federal policies provide the answer. In recent years, President Obama enacted a federal grant program to fund teen pregnancy prevention programs, called the Teen Pregnancy Prevention Initiative. The Initiative allows evidence-based teen pregnancy prevention programs to apply for grant funding. Also, the Initiative funds research to develop and evaluate different strategies to prevent teen pregnancy. "TPPI was funded at \$105million in FY 2012, which includes:

1. $\$ 75$ million available for Tier 1 grants to replicate evidencebased programs that have been proven effective through rigorous evaluation to reduce teen pregnancy, behavioral risk factors underlying teen pregnancy, or other associated risk factors. There are 75 cooperative agreements under Tier 1.

2. \$25million available for Tier 2 research and demonstration grants to develop, replicate, refine, and test additional models and innovative strategies for preventing teen pregnancy. There are 19 cooperative agreements for Tier 2 ". ${ }^{23}$

While the Initiative does not implement strict requirements or standards for their funded sexual education programs, the Healthy Teens Act would establish these standards on the state level. Programs seeking funding would need to meet the funding requirements. The HTA would provide further funding and assistance to comprehensive sexual education programs in New York State, largely targeted to school districts and community organizations like Planned Parenthood. This would be beyond the scope of the Initiative, since it is a national plan and does not focus on any particular state. As a result, only 5 programs in New York State received funding for maintaining sexual education programs. ${ }^{28}$ Only 4 of these programs were actually comprehensive; 1 was an abstinence-only program. ${ }^{29}$ Unfortunately, these programs were not tied to Onondaga County or Central New York.

The last criteria for policy evaluation are political feasibility and community acceptance. The Initiative is a very important step, on a federal level, for comprehensive teen pregnancy prevention programs. Due to its success, the Initiative is changing the way comprehensive sexual education is perceived and approached. "Leading public health and medical professional organizations all stress the need for sexuality education that includes messages about abstinence and provides young people with information about contraception for the prevention of teen pregnancy, HIV/AIDS, and other STDs. Supporters of comprehensive sexual education include: The American Academy of Pediatrics, the American College of Obstetricians and 
Gynecologists, the American Medical Association, the American Nurses Association, the American Psychological Association, the American Public Health Association, the Institute of Medicine, and the Society of Adolescent Health and Medicine". ${ }^{30}$ Most importantly, the Initiative marks comprehensive sexual education as a priority and paves the way for future comprehensive sexual education policies, such as the Healthy Teens Act. This addresses the question of political feasibility of the proposed legislation.

According to a recent public poll, "New Yorkers overwhelmingly support a State-funded, comprehensive approach to sex education for our young people. $72 \%$ of New York voters polled indicated support for the Healthy Teens Act. Nearly $90 \%$ of voters agreed that students should be taught about contraception and the prevention of STIs". ${ }^{28}$ Public support plays a key role in the implementation and potential success of the Healthy Teens Act, however there is little public awareness of the bill. Thankfully, many New York state institutions and organizations have pledged their support of the Healthy Teens
Act. Planned Parenthood of New York City, The New York Civil Liberties Union (NYCLU), and the New York City Bar have all issued memos in support of the Healthy Teens Act. These organizations, and others, recognize the need for funding comprehensive sexual education programs and establishing standards for such education. According to Planned Parenthood of New York City "although New York State funds a small number of pregnancy prevention programs, this is the only dedicated state money that supports any type of sex education that teaches about contraception in addition to abstinence. The State does not even provide funding for the implementation of state-mandated HIV/AIDS education. This under-funded, piecemeal approach to health education leaves most New York youth without vital, lifesaving information and skills". ${ }^{28}$ These memos are directly calling out abstinence-only and abstinence-plus approaches to sexual education. Many agencies currently feel that these approaches are failing and that something else must be done to prevent teen pregnancy in New York State.

Table I Summary Matrix for Teen Pregnancy Policies

\begin{tabular}{|c|c|c|c|c|c|}
\hline & Effectiveness & Efficiency & $\begin{array}{l}\text { Cost } \\
\text { effectiveness }\end{array}$ & $\begin{array}{l}\text { Institutional } \\
\text { constraints }\end{array}$ & $\begin{array}{l}\text { Community acceptance } \& \\
\text { political feasibility }\end{array}$ \\
\hline $\begin{array}{l}\text { Abstinence- } \\
\text { Only }\end{array}$ & Low & Low & Low & Low & Low \\
\hline Abstinence-Plus & Low/Moderate & Moderate & Moderate & Low & Moderate \\
\hline Comprehensive & High & High & High & Moderate & High \\
\hline
\end{tabular}

At the present time, The Healthy Teens Act is only a proposed legislation. It "passed Assembly in 2005 and was delivered to the Senate Rules Committee, where no further action was taken. The Sex and Law Committee has analyzed the Healthy Teens Act and believes that it represents a fair and balanced approach to this divisive issue. ${ }^{31}$ "The bill was reintroduced in January 2009 and carried over from the previous legislative session. It passed the Assembly 129-16, but failed to move out of committee in the Senate. It was returned to the Assembly in January 2010, but no further action was taken". ${ }^{31-38}$ This report should be considered a call to action for the implementation of a new teen pregnancy prevention policy. New York State has an obligation to offer comprehensive, accurate, and effective information to teens. The Healthy Teens Act is a crucial step in providing teens with the knowledge and skills necessary to protect their sexual and reproductive health. ${ }^{39-42}$ Organizations as well as New York State citizens should pledge their support for the Healthy Teens Act (Table $1)$.

\section{Action plan for onondaga county}

1) Proposed Interventions for Local Organizations and Community Agencies such as

Planned Parenthood, Family Planning Service, Syracuse Youth City Council, and People's A.M.E. Zion Church:

1. Use social media to advertise the Healthy Teens Act and its potential benefits.

2. Hold lobbying sessions in support of the Healthy Teens Act.

3. Create and send memos of support of the Healthy Teens Act to policymakers.

4. Form a policy task force with members from different organizations.
5. Create and implement a sexual education curriculum designed for students who have dropped out of school.

6. Create media awareness of the teen pregnancy problem and proposed Healthy Teens Act.

7. Create and distribute a public petition in support of the Healthy Teens Act.

1. Goals

2. To stimulate public support and awareness of the Healthy Teens Act.

3. To create awareness of the benefits of comprehensive sexual education for communities with high rates of teen pregnancy.

4. To target drop-out students who are at the highest risk of teen pregnancy and STDs.

5. To create awareness of New York State's lack of sexual education standards.

6. To lobby the Healthy Teens Act to policymakers.

1. Proposed Interventions for schools such as Syracuse City School District:

2. Target middle school populations for educational interventions in order to combat the high drop-out rate.

3. Partner with local organizations and community agencies in the development of a sexual education program designed for dropout students.

4. Hold informational meetings on the Healthy Teens Act for members of the PTA's and PTO's.

5. Send informational brochures of local organizations and their available health services to students. 
1. Goals

2. To target drop-out students who are at the highest risk of teen pregnancy and STDs.

3. To gain support for the Healthy Teens Act from PTA's and PTO's while fully educating parents on the benefits of comprehensive sexual education.

4. To encourage parental involvement in the implementation of a comprehensive sexual education program.

5. To increase student awareness and utilization of local health services.

\section{Acknowledgements}

None.

\section{Conflict of interest}

The author declares no conflict of interest.

\section{References}

1. Hydraulic Fracturing Under the Safe Drinking Water Act. Water: Hydraulic Fracturing. United States Environmental Protection Agency; 2013.

2. Albert B. Parental Influence and Teen Pregnancy. National Campaign to Prevent Teen Pregnancy, 2008.

3. Philip C, Rob C. National Initiative on Teenage Pregnancy. AMSA. 1999:6-15.

4. Bennet S, Assefi N. School-based Teenage Pregnancy Prevention Programs: A Systematic Review of Randomized Controlled Trials. Journal of Adolescent Health. 2005;36(1):72-81.

5. Benson B, Miller B, Galbraith. Family Relationships and Adolescent Pregnancy Risk: A Research Synthesis. Developmental Review. 2001;21(1):1-38

6. Castillo M. US Teen Pregnancy Rates at an All-Time Low Across All Ethnicities. CBS News Online, CBS News; 2012.

7. CDC Data and Statistics: Reproductive Health and Teen Pregnancy.

8. Teen Pregnancy Prevention Strategic Plan. Commonwealth of Kentucky Department of Public Health, Division of Women's Health; 2010.

9. Cornerstone Consulting Group, Inc. Teen Pregnancy: Policy's Role in Prevention. 2003.

10. Fothergill K. School-Based Health Centers. USA: Advocates for Youth; 1997.

11. Furstenberg F. The History of Teenage Child bearingasa Social Problem.

12. Gavin L. Teen Pregnancy Study Report. Center for Disease Control; 2012.

13. Guttmacher Institute. State Policies in Brief: Sex and HIV Education. 2013.

14. Huang L, Hart B, Daro D. Improving Services for Pregnant Women and Children 0-1 in New York State. USA: University of Chicago; 2010. $62 \mathrm{p}$.

15. Kann L. HIV, Other STD and Pregnancy Prevention Education in Public Secondary Schools. Center for Disease Control; 2012. 61(13):222-228.

16. Kohli V, Nyberg K. Teen Pregnancy Prevention through Education. USA: California State University; 1995. 75 p.

17. Kost K, Henshaw S, Carlin L. U.S. Teenage Pregnancies, Births and Abortions: National and State Trends and Trends by Race and Ethnicity. 2010.
18. Kirby D. Emerging Answers: Research Findings on Programs to Reduce Teen Pregnancy and Sexually Transmitted Diseases. National Campaign to Prevent Teen Pregnancy, 2007.

19. Miller B, Benson B, Galbraith K. Family Relationships and Adolescent Pregnancy Risk: A Research Synthesis. Developmental Review. 2001;21(1):1-38.

20. National Campaign to Prevent Teen and Unplanned Pregnancy. Federal Funding for Teen Pregnancy Prevention Programs.

21. New M. Contraception Programs and Teen Pregnancy Rates. National Review. 2012.

22. New York City Bar. Report on Legislation: The Healthy Teens Act.

23. New York Civil Liberties Union. The Healthy Teens Act. S.1342/A.2856.

24. New York State Department of Health. Onondaga County Teenage Pregnancy Rate.

25. New York State Department of Health (2006-2008) Teen Pregnancy Rates by Zip Code.

26. Onondaga County Health Department. Annual Report. 2011.

27. Perez V. Teenage Pregnancy: An Historical Legislative Analysis. Syracuse University Writing Program; 2002.

28. Peterson-Beadle A. Teen Pregnancies Highest in States with Abstinence-Only Policies. 2012.

29. Planned Parenthood of New York City. Memorandum In Support:A.2856/S.1342 The Healthy Teens Act. 2007.

30. Rudlin K. Teen Pregnancy Risk Factors. Women's Health Queensland Wide. 2012.

31. Sanghavi D. Why Teen Pregnancy Rates Have Dropped? Washington Post; 2012.

32. New York State Profile. Siecus. 2010.

33. The President's Teen Pregnancy Prevention Initiative: Providing Young People the Information and Skills They Need. Siecus. 2010.

34. Senate-Assembly. Regular Sessions. State of New York, USA, S.1342, A.2856.

35. Syracuse City School District Graduation Rates by Race/Ethnicity (2010-2011).

36. Sutherlin E. Teen Pregnancy Linked to Pre-Teen Literacy Levels. American Public Health Association; 2012.

37. Tiffany Lloyd, Family Planning Service Health Education Coordinator.

38. USA Guide to Community Preventive Services. Preventing HIV/ AIDS, other STIs, and Teen pregnancy: Group-based Abstinence Education Interventions for Adolescents. Preventing HIV/AIDS, other STIs, and teen pregnancy: group-based comprehensive risk reduction interventions for adolescents.

39. American Community Survey (2007-2009) data, US Census Bureau, USA.

40. US Department of Health and Human Services. Teen Pregnancy Prevention and Evidence-Based Programs. Office of Adolescent Health USA. 2013.

41. Youth Risk Behavior Student Survey, CDC. HIV, Other STD, and Teen Pregnancy Prevention and New York Students USA. 2011.

42. Woodward L, Fergusson D, Horwood J. Risk Factors and Life Processes Associate with Teenage Pregnancy: Results of a Prospective Study From Birth to 20 Years. Journal of Marriage and Family. 2012;63(4):11701184 . 